\title{
胶质细胞: 脑功能与疾病研究不可或缺的领域
}

\author{
何成 \\ 第二军医大学神经科学研究所, 分子神经生物学教育部重点实验室, 上海 200433 \\ E-mail: chenghe@smmu.edu.cn
}

收稿日期: 2015-08-03; 接受日期: 2015-08-11; 网络版发表日期: 2015-08-19

国家自然科学基金(批准号: 31130024, 81461138035, 31371068)和国家重点基础研究发展计划(批准号: 2011CB504401)资助

人类有别于其他动物的根本在于人类独特的大 脑. 解密大脑工作原理, 促进人脑健康, 是自然科学 领域最有吸引力、最具挑战性的命题. 2013 年以来, 美国、欧洲联盟相继提出了各自的脑研究计划; 在国 内学术界不解努力和政府的高度关注下, 中国脑计 划也在酝酿之中, 并且推出在即. 在制定中国的脑研 究计划时, 审慎分析美国、欧盟脑计划的内涵, 对于 发挥我国脑科学研究后发优势, 形成特色, 实现超越, 无疑具有重要意义.

毫无例外, 美国、欧盟的脑研究计划关注的都是 神经元的问题, 无论是其联结、活动还是模拟. 然而, 值得注意的是, 人脑内神经细胞主要包括两大类: 占 细胞总数约 $10 \%$ 的神经元和占约 $90 \%$ 的神经胶质细 胞. 神经元能对外界刺激产生反应, 并产生“全或无” 的动作电位, 而神经胶质细胞不能产生动作电位, 这 是两者的最基本区别, 也由此形成了传统思维定式: 神经元是主角, 胶质细胞是“可有可无”的配角. 然而, 近年来越来越多的证据表明, 胶质细胞可能掌握着 认识脑、保护脑的密钥.

脑内神经胶质细胞主要有 3 种: 星形胶质细胞、 少突胶质细胞和小胶质细胞 ${ }^{[1]}$. 星形胶质细胞是脑内 数量最多的胶质细胞, 其总体积接近脑容量的 $1 / 2$. 星形胶质细胞对神经元代谢起支持作用，不仅能够 为神经元提供额外的产能底物乳酸, 还能够调节胞
外钾离子、谷氨酸、氢离子的浓度. 在大脑灰质, 一 个星形胶质细胞的突起可以包裹成千上万的神经元 突触，与突触前和突触后结构共同构成“三组分突 触”，从而能够更加精确、快速、有效地调节突触传 递; 星形胶质细胞之间形成的缝隙连接, 能够有效扩 布钙离子等小分子, 实现信息在较大范围传播. 少突 胶质细胞是中枢神经轴突的成鞘细胞. 髓鞘使得动 作电位实现“跳跃性”快速传播; 髓鞘还能够保护轴 突, 支持轴突能量与物质代谢. 新近的研究显示, 脑 内髓鞘的动态变化, 可能通过影响轴突兴奋性传递 速度, 进而调节突触与环路信息加工; 工作记忆与特 定脑区的髓鞘变化密切相关 ${ }^{[2]}$. 小胶质细胞是驻留在 中枢神经系统的免疫细胞, 它们对大脑起监视作用, 能够及时探知细胞损伤而被激活, 从而发挥吞噬、分 泌等免疫功能. 最近发现, 小胶质细胞还能够探知神 经元的活动性, 参与修剪突触连接, 重塑神经环路. 因而, 对脑功能的认识可能不应仅停留在神经元突 触和神经环路的“点、线、面”的层次，从胶质细胞的 角度深入分析，可能使人们能够更加“立体”地认识 大脑.

胶质细胞与脑疾病的发生、发展关系极其密切. 小胶质细胞几乎参与了所有神经疾病的病理过程; 髓鞘对于缺血、缺氧、炎症反应等损伤因素反应敏感, 脱髓鞘广泛存在于多发性硬化、缺血缺氧性脑病、新

引用格式: 何成. 胶质细胞: 脑功能与疾病研究不可或缺的领域. 中国科学: 生命科学, 2016, 46: 214-215

He C. Neuroglia: an indispensable field to explore brain function and dysfunction. Sci Sin Vitae, 2016, 46: 214-215, doi: 10.1360/N052015-00230 
生儿脑室周围软化等疾病; 在创伤、中风等急性脑损 伤中, 胶质环境改善对神经元保护与再生起至关重 要的作用. 过去认为是神经元产生问题的神经变性 疾病和精神疾病的发病根源可能在胶质细胞. 例如, 有研究发现, 星形胶质细胞上的多巴胺 II 型受体参 与抑制神经炎性反应，与帕金森病等多巴胺能神经 元变性有关 ${ }^{[3]}$; 星形胶质细胞来源的三磷酸腺式 (adenosine triphosphate, ATP) 参与调节抑郁样行家 为 ${ }^{[4]}$. 胶质细胞对神经元的支持保护作用以及信息传 递调制作用, 体现出动态平衡性、广泛性、相对慢速 等特点. 这与神经退行性病变等渐进性发病特征相 吻合, 或许也是目前未能发现明显神经元病理变化
的抑郁症等认知相关疾病的“病根”所在.

美国国立卫生研究院的 Fields ${ }^{[5]}$ 在《自然》撰文 批评美国脑计划, 他认为美国脑计划过分强调对神 经元的描述, 而忽视了胶质细胞的作用, 可能会导致 该计划最终难以实现预期目标. 即将出炉的中国脑 计划，不应步美国、欧盟脑计划后尘，仅关注神经元； 我们把研究重点放在脑高级功能及其相关疾病方面 时, 应重视胶质细胞的研究. 神经元网络的形成、维 持、运行、重构都有赖于胶质细胞. 离开胶质细胞, 神 经元网络只是一堆冰冷的、易于崩溃的复杂电子线路 而已, 它不是带给我们快乐、激情、恐惧、焦虑、抑 郁、痛苦 $\cdots . .$. 的人类大脑.

\section{参考文献}

1 Verkhratsky A, Butt A. Glial Physiology and Pathophysiology. New Jersey: Wiley-Blackwell. 2013

2 Fields R D, Woo D H, Basser P J. Glial regulation of the neuronal connectome through local and long-distant communication. Neuron, 2015, 86: 374-386

3 Shao W, Zhang S Z, Tang M, et al. Suppression of neuroinflammation by astrocytic dopamine D2 receptors via $\alpha B-c r y s t a l l i n$. Nature, 2013, 494: 90-94

4 Cao X, Li L P, Wang Q, et al. Astrocyte-derived ATP modulates depressive-like behaviors. Nat Med, 2013, 19: 773-777

5 Fields R D. Map the other brain. Nature, 2013, 501: 25-27 